\title{
Managing the Institutionalisation of Mode 2 Knowledge Production
}

\author{
Merle Jacob
}

\begin{abstract}
The combination of decreasing public allocations to universities with relevance pressure from both governments and private corporations has contributed to the rise of the phenomenon of Mode 2 knowledge production. Many Mode 2 researchers have been encouraged and stimulated to experiment with new forms of organizing the production of knowledge while remaining within the context of the traditional European university. This has resulted in the emergence of number of new institutional formats including university based research centers or institutes and long-term research programs have emerged. While there has been a lively debate about the transitions in the landscape of knowledge production, it has failed to address its organizational details. A detailed look at transition cases pushed forward by political programs promoting knowledge exchange between university and industry shows that the institutionalization of Mode 2 is accompanied by significant problems for the management of research and the production of knowledge.
\end{abstract}

Keywords: Knowledge production, research management, university industry relation

Several studies have chronicled the changing landscape of knowledge production in European public universities and there is a general consensus that national (i.e. individual European countries) and regional (European Union) policies for funding research are increasingly converging (Martin, 1999; OECD, 1998; Kuhlmann, 2001; Peterson \& Sharp, 1998). This convergence is manifested in among other things: (1) a focus on collaborative research and tied funding; (2) coordination of research priorities be- tween nation states and the European Union; (3) a shift in the general objective of research policy from funding science to funding innovation; (4) emphasis on the production of custom made knowledge for discrete sets of stakeholder and/or user groups and (5) an increased focus on different types of accountability measures for monitoring and evaluating university research output. Although this paper will focus exclusively on European public universities, it is important to observe that the 
macro policy orientation which gives rise to the phenomena under discussion is not unique to Europe and may also be observed in the USA. In fact, one of the more succinct descriptions of the macro policy shift is captured in a statement made by a leading congressional figure in US science policy, which described the policymakers' position in the following words:

The scientific community must seek to establish a new contract with policy makers based not on demands for autonomy and ever increasing funds, but on the implementation of an explicit research agenda rooted in [social] goals (Brown, 1992 cited in Guston \& Kenniston, 1994: 6-7).

This change in the expectations of science has had consequences for the way in which research is organised and conducted and some science policy researchers have attempted to envision the substantive form and content of its organisational and epistemological consequences. One such vision is outlined in Gibbons et al. (1994)controversial publication "The New Production of Knowledge", suggesting that a new mode of production ("Mode 2") has emerged. The Mode 2 thesis, together with the changing context for research in European universities, has been fertile ground for researchers in so far as the topic has spawned countless books and articles. The focus of this nascent body of knowledge may be categorised in four main groups: the implications of universityindustry collaboration for academic freedom (Delanty, 2001; Pritchard, 1998); the implications of Mode 2 knowledge production for the quality of science (Fujigaki \& Leydesdorff, 2000; Demeritt, 2000); the impact of accountability measures on the organisation of the university and related issues such as the social function of the university (Evans, 1999; Delanty, 2001, Rappert, 1995); the impact of the commodification of knowledge (role of patents, licenses and other arrangements for exclusive access) (Behrens \& Gray, 2001; Slaughter \& Leslie, 1997; Rappert et al., 1999).

These discussions have been largely polemical partly because many of the issues are not amenable to any other type of research. Behrens and Gray, (2001) reported that a survey of issues (produced over the last five years) of a number of prominent S\&T policy, evaluation research and higher education journals reveal few (4) empirical studies on cooperative research. Although Behrens and Gray's search was focused on finding papers that deal with unintended consequences of cooperative research, one can assume that their findings will also hold for the treatment of management of cooperative research.

Despite the burgeoning literature about issues generated by Mode 2 like phenomena, the existence of Mode 2 remains a contested issue. Given this, the present paper will assume that we can accept a generalised version of the Mode 2 thesis while reserving judgement on the details of specific postulates in the argument. Adopting this position, however, still leaves an important question unresolved i.e. how does Mode 2 knowledge production actually function? This is a multi-faceted question which includes dimensions such as: the nature of Mode 2 knowledge; the way in which Mode 2 knowledge production is organised and its commensurability and impact on the other demands that constitute academic life such as educating 
future generations.

This article addresses one aspect of this matrix of questions, i.e. the organisation of Mode 2 knowledge production by focusing on a still neglected dimension of organising i.e. the processes that ensue once an institutional context for the production of Mode 2 knowledge has been created. The article proceeds as follows. The following section provides the background by briefly outlining some of the main issues in the Mode 2 debate of relevance to the problem to be discussed here. The third section exemplifies how Mode 2 research is organised in practice by providing two composite pictures of the organisational structure of Mode 2 research institutes and outlining some of the management problems that they have encountered. These composite pictures are intended to function as devices for providing the reader with a feel for the organisational context in which the management issues discussed emerged and are resolved. The concluding section will attempt to reflect on the management problems from three different vantage points which I argue are starting points for resolving the long and shortterm aspects of the challenges presented by Mode 2 institutes.

\section{Uncharted Territory: Mode 2 and Research Management}

Since the existence of Mode 2 as a special form of knowledge production remains a contested issue, it is necessary for background purposes to provide a brief overview of the nature of the controversy regarding the Mode 2 thesis. In arguing for the Mode 2 thesis, Gibbons et al. (1994) make the following claim:

\begin{abstract}
"we are now seeing fundamental changes in the ways in which scientific, social and cultural knowledge is produced.... [T] his trend marks a distinct shift towards a new mode of knowledge production which is replacing or reforming established institutions, disciplines, practices and policies" (back cover of book).
\end{abstract}

The detractors of the Mode 2 thesis fall into two categories: (1) those who contest the existence of Mode 2 on the grounds that Gibbons et al. provide very little systematic evidence for their claim (Weingart, 1997; Godin, 1998) and those who maintain that the claim is exaggerated in so far as historically, knowledge production in the university has never been characterised by a monolithic set of practices and guidelines as implied in the Gibbons et al. description of Mode 1 (Martin, 2001). Martin further maintains that one way of reading the current situation in university science is that it is establishing a balance between Mode 1 and Mode 2 knowledge production after decades of an imbalance in favour of Mode 1.

These arguments are all reasonable and Nowotny and her colleagues concede some of this ground, quite unnecessarily in my view, but this decision may have something to do with the fact that they have not attempted to provide empirical substantiation. In "Rethinking Science" they state that "there is not much evidence that the development of a Knowledge Society has weakened the hegemony of traditional 'knowledge' institutions such as universities." (Nowotny et al., 2001: 16). The authors further maintain that while their new account "endorses the argument that radical changes have taken place in the organisational structures within which 
knowledge is produced and its social (and professional) practices, it offers little support for the assertion that core epistemologies and methodologies are also changing." (2001: 16) In other words, Nowotny and colleagues are conceding their critics' claim about the lack of systematic evidence but only with respect to the epistemological reading of the Mode 2 thesis.

The problem with the above is that it forces us to tacitly accept a view of science which entails the postulate that the epistemology of science is hermetically sealed off from the social and organisational arrangements for the production of knowledge. Accepting such an argument not only puts into question a large body of findings that show the opposite in the social studies of science (cf among others Platt, 1996; Shapin, 1994; Fuller, 1997), but also leaves a number of aspects of the lived reality of Mode 1 and Mode 2 unexplained. I shall provide two examples to illustrate the second part of this point. For those working in what may for the sake of argument be called Mode 1 , their lived reality is that the social and epistemological stability and security that the Gibbons et al. account attributes to Mode 1 is constantly being threatened and reduced. For example, tenure is now changing from the homogenous situation of a guaranteed position up to retirement to a heterogeneous arrangement, which implies a career, constructed of several long-term contracts of 3-5 years. Additionally, there is the in between modes alternative where the tenured scientist may still be subject to the pressures of contract research in order to raise money for doctoral students or to preserve a balance between research and teaching in her career.
Likewise, for those in Mode 2, the situation differs so radically across countries and universities that it is difficult to even construct a generalised account of a typical Mode 2 career or institution. As Ziman (2000:61) pointed out, "the small print of everyday business can change out of all recognition long before this shows up in the headlines of an ethos." This implies that attempts to describe Mode 2 are doomed to either paint broad landscapes of abstractions and imperialistic claims or stick to rich and thickly contextualised descriptions. The first are easily knocked down by their inability to provide empirical backing and the second by the counter claim that one or two cases no matter how striking do not constitute a trend.

With these difficulties in mind the following subsection will attempt to straddle both approaches by outlining a generalised description, as well as specifics of the Mode 2 institutes. These examples are composites constructed from existing institutions in Sweden and the UK. Some of the distinguishing features of the institutions have been removed such as what type of research they do in order to prevent them from being recognised. I have also alternatively suppressed or explicated some aspects of the institutional history and culture to bring into sharp relief the contours of Mode 2 that are more difficult to discern otherwise and to preserve anonymity. The examples of management problems both anecdotal and analytical are, however, lifted directly from the particular contexts. Each account will have two parts; the first will be a description of the institutional structure with a broad sketch of how the institute came into being and its context. The second part will be a discussion of 
some of the typical management problems that the institute has encountered.

The data on management problems for this paper was collected from interviews and the institutional descriptions are compiled from interviews and web pages from 12 Mode 2 institutes. All aspects of the material is kept anonymous.

\section{Organising Mode 2 Knowledge Production}

Describing a Mode 2 institute is an issue rendered complex by the idiosyncratic gloss that national and institutional differences at the university level can lend to these institutes. A further problem is that I restrict myself to a certain type of Mode 2 institute and that is the university-based institute. This means that public research institutions such as industrial laboratories and other types of freestanding research institutes e.g. government research institutes, are not included in the category of Mode 2 institutions discussed here. There are several reasons for leaving these institutions out of this narrative. The most important of these is that the issue that I want to address here is the specific management problems that arise in semi-autonomous research institutions within the university.

One reason for singling out this category of semi-autonomous institutions is that due to their relative newness, as well as their intimate connection to the university, the management problems in these settings have not been addressed in the research management literature. A second reason is that Mode 2 institutes should be distinguished from public research institutes because the latter usually enjoy some kind of guaranteed base funding from the state and compete openly for the remaining portion of their funding. This situation provides some kind of baseline institutional security with respect to recruiting staff and setting up long term research programs or trajectories that is absent in the cases that are the subject of this article. Thirdly, public research institutions in Europe are themselves going through some of the same pressures as the university and the impact of these perturbations on this tradition of knowledge production and its management deserves separate treatment (cf. Cohen et al., 1999; Potí \& Reale, 2000). Fourthly, a defining characteristic of public research institutes is that their very existence is often premised on their role vis a vis university science. This is in most cases a division of labour which assumes that public research organisations will provide a direct service function to a specified customer in the form of evidence based knowledge, advice, etc. Finally, scientists working in public research institutes are usually quite settled in this as an alternative way of pursuing a research career from the university. As I will show below it is the diffusion of the knowledge goals of public research institutes without the attendant security and adjustments at the level of career trajectories taken together with the symbiotic relationship between Mode 2 institutes and the traditional yet transforming university that creates the special kinds of management tensions that I describe below.

Reasoning from the above one may argue that a Mode 2 institute is defined by the following characteristics: it is a spin out institution from the university that remains organisationally a part of the university; the institute is niched to 
perform research and teaching tasks that are often multi- or transdisciplinary; it is to a large extent staffed by temporary labour; the knowledge profile or knowledge development goals of the institute are less rigidly defined than that of a disciplinary based department but there are often clearly defined lines of knowledge interest that are independent of the specific client needs outlined in its project portfolio; the organisation is characterised by a high degree of agility with respect to how it leverages its competence vis a vis the nature of the market.

This is not an exhaustive list of the characteristics of a Mode 2 institute and one will find that several of them will have additional characteristics or nuances of the above list depending on their history and setting. Nevertheless the above suffices as a map.

\section{CASE A:The Emergent Mode 2 Institute}

Case A is a small university based research institute that specialises in science policy and evaluation research, which has been in existence for a total of seven years. The institute functions as a think tank for science policymakers, conducts its own basic research and acts as a resource for conducting evaluation of university research and education. Its aim is to gradually expand its core team of clients - the majority of whom are national - to a regional one. The client list of the institute includes universities, government departments and international organisations. The impetus for founding the institute came from a combination of initiatives spearheaded by the university, the majority funders and the founding team of researchers respectively. The most significant of these in- clude the policy on the part of faculty administration of encouraging interdisciplinary projects to migrate to spaces between departments rather than at departments. This is manifested in a series of administrative rules and practices that encourage senior researchers with a long history of externally funded projects to create such centres by providing some matching start up resources. Another factor that prompted the formation of the institute was increased availability of funding for evaluation research as a result of a shift in government policy.

All of the institute's research funding is project based and there is no overall grant for covering infrastructure and running costs. During the first two years of the institute's life, the university provided a small grant, which took the form of a holiday from running costs such as offices, telephone and other information technology services.

The researchers at the institute are further integrated with the rest of the university through two main vehicles: (a) supervision of doctoral students and (b) their participation in two graduate programmes at the Masters level focused on the institute's speciality. These programmes are staffed by faculty from the university, as well as institute staff. The primary institutional partners of the institute at its own university are the departments with which they share teaching. The academic leader of the institute is also chair of one of these departments.

The leadership structure of the institute is divided into an administrative and an academic leadership. The academic leader is a researcher who has attained the rank of professor whose duties include among other things: to sustain the project portfolio of the institute 
by designing new projects and conducting research, use her professional reputation to draw other kinds of soft money; provide an academic celebrity status, which in turn attracts young, gifted researchers to the institute.

The bulk of administrative work generated by the institute is dealt with by university administration but onsite matters such as recruitment and day-today management are the responsibility of the administrative leader. This individual is not a full time administrator but another senior academic who has in addition to this role her own project research and student supervision. The remainder of the institute staff are further subdivided into administration and research (postdoctoral researchers and doctoral students who work as part time research assistants). Each project at the institute has the following structure: senior researcher or principal investigator, postdoc, research assistant. Some individuals work on several projects but usually for the same senior researcher. Contracts range from three months to one year regardless of the life span of the project to which the individual is attached.

\section{Case B:The Policy Assisted Mode 2 Institute}

Case B is a four-year programme for research and education in management, funded by a consortium comprised of a public research council and a number of industrial partners. The level of financing from the industrial partners ranges from full term commitment in the form of an annual subscription fee to project based commitment. The impetus for starting the centre came from the re- searchers themselves as a reaction to an open call for proposals from a newly started research council. The centre was the outcome of several re-workings of the initial proposal after consultation with the granting agency and the partner firms, which were chosen as the collaborators for the research programme.

Apart from the doctoral education, there is no overarching research plan or long-term knowledge goals except for an explicit commitment to carrying out a number of custom and, possibly, subscription research projects designed and executed by faculty members, students, and practitioners from the partner companies. It is further understood that these two tasks are to be implemented in an action science framework with all research projects being designed and implemented together with practitioners. The choice of research ideology is the outcome of a compromise between the individual researchers own prior experience and the preconditions for receiving funding from the centre's largest financier. Unlike Case A above, the founders of this programme have worked very hard at constructing a vision of the organisation that all members are expected to relate to. This vision is based on positioning the organisation as middle ground between the university and industry and the preferred research ideology. Ownership of the content and interpretation of this vision is strictly the prerogative of a small sub-group of the founding group. It is the vision and not the knowledge produced by the programme that is seen as the source of its innovative edge and contribution. Employees are expected to embody this vision and are encouraged to embrace corporate rather than academic values. 
The programme structure is an example of a virtual organisation. The doctoral education is formally the responsibility of two different universities and the students are equally distributed between these two institutions. All students are part time and are employed in various companies. The programme is explicitly marketed as a further education, which will equip students to perform better in their corporate roles. Unlike most other programmes of doctoral study, the students are not expected to come from any one or clearly defined academic background. In fact, whereas the eligibility requirements with respect to the nature of the prospective students' industrial experience and position were very detailed and demanding the academic requirements were extremely loosely defined.

The supervision of the students is outsourced to a number of researchers, the majority of whom are not part of the research programme. This arrangement also holds for the courses offered in the programme. The projects in the programme administration do not form a coherent portfolio and are the property of the individual researchers who have joined the programme. Administration of all projects is outsourced to a second organisation, which is owned by a consortium of universities that includes the two universities participating in the programme. All members of staff are employed on short-term contracts ranging from six months to one year with option for renewal.

\section{Differences Between the Cases}

Although at first sight the above two institutions may appear to be identical in their organisational structure, there are important differences between them, one being that Case $\mathrm{B}$ is a research programme built around a doctoral school. The school is a fixed term event, i.e. it will not be continued, and the future of the research programme is an open question since the base funding is intended to finance the school. Thus, Case B may be argued as being a temporary network with a character that is very much reminiscent of extension or outreach programmes that universities have traditionally designed e.g. agricultural extension services or MBAs or Masters of Public Administration. In this sense Case B may arguably be likened to a repackaging of an old formula for further education, which universities have used over several decades. As in all cases, the difference is in small details such as the way in which the doctoral programme is leveraged. I have dubbed this Case as policy assisted to highlight the important role played by the funding agency in shaping programme structure and content. This is also to be distinguished from Case A which I describe as emergent because of it being a product of the university's own policy.

A second difference is in the way in which the university - institute interface is structured. Case A might be said to have a number of points of interface with departments at the university; many of which are dependent on mutual needs on an organisation to organisation level, as well as personal networks between individual researchers. Case B, however, has a more structured but complex interface with the universities it works with. This is partly because the main activity of Case B is education and this activity must be officially located at a department. Thus, students 
are all registered with specific departments but belong to the programme. There is very little interaction between the students in the programme and other doctoral students at the university since Case B students follow for the most part a specially designed curriculum and study only part-time. This creates a situation where the programme behaves as an independent organisation but is not recognised by the separate university administrations as anything more than a programme. This taken together with the fact that the vision of Case B explicitly constructs the institute as an organisational form that is necessary because of the 'flaws of the traditional academy' creates a distance between this institute and its host universities.

A third and final difference between the two organisations is that Case B is more of a broker organisation that treats the university as a supplier of competent labour and certification for a product, which it delivers to its clients, the students and projects. Case A, when compared to Case B looks like what a department may look like in a university with an entrepreneurial culture. These differences as we will show manifest themselves at the level of the management challenges experienced in the two settings.

\section{Managing Mode 2}

This section will be devoted to describing and analysing some of the typical management problems that were encountered in the institutions described. The discussion of these problems will be structured into a focus on leadership and the interface between Mode 2 centres and the host university on one hand and between centres and funders on the other.

\section{The Leadership Dilemma}

Leadership and management have always received a lukewarm reception in the academic world particularly when one bears in mind academe's espoused theory of a meritocracy in which knowledge claims are constantly open to revision (cf. Popper's falsification thesis) and the merit of a challenge is judged on its own terms rather than on the status of the challenger (cf. Merton's norm of organised scepticism). Although sociologists of science have long since critiqued this espoused theory, they would concede that the everyday relation of academics to leadership and management is to some extent coloured by this espoused theory (Pinch, 1990; Bourdieu, 1988; Fuller, 1997). The result of which is that in contrast to the corporate world where both leadership and management are regarded as tasks in themselves, academic leadership and to a lesser extent management are seen as by products of exemplary performance of the core tasks: research and teaching.

An incident that occurred in Case B may serve as an example. Tom and Jerry, the director and assistant director respectively are dissatisfied with the present organisational structure for research, which they regard as loose and too ad hoc. They would like a more coherent project portfolio and a clear research profile for the programme, which would be more capable of attracting corporate clients. Jerry suggests that they should have a research plan and they should appoint an office manager. They ask one of the more senior researchers 
to develop the research mission statement and appoint Michael, one of Tom's recently graduated $\mathrm{PhD}$ students, to the office management position. An announcement of Michael's appointment is made via email to the entire organisation, but no details as to duties are given in this announcement nor are they given to Michael. Michael's first official act in this new capacity was ordering a new set of business cards in which he lists his new title as research manager. His second was to ask all his colleagues working in the research part of the organisation to a meeting to discuss their projects, staffing needs, etc. They all agree that it is an excellent idea, but it still takes one month to get the group which is four persons including Michael to agree on a date for the meeting.

The meeting turns out to be quite different from what Michael had expected since only the barest details about prospective and ongoing projects are shared, although everyone was eager to tell him their complaints about minor things such as doors not working or glitches in the office landscape. After four such meetings, Michael notices that: (1) his colleagues continue to discuss prospective bids and resource needs with Tom and Jerry; (2) interest in attending the meetings is beginning to wane; (3) more and more of his time seems to be devoted to mundane administrative fallout from his colleagues projects and (4) his legitimacy as a researcher seems to be under threat as he has no new projects of his own and his research speciality sticks out as an afterthought in the newly presented mission statement. He finally complains to Tom and Jerry and a meeting was convened to discuss the issue. The responses are described below.
One member of the research team said that she felt that Michael had over interpreted his brief as office manager and tried to use that to get a leadership position in the research team for which he was not qualified. Another said that in his view office managers manage the office and that meant the physical environment and he thought that the fact that Michael accepted this post meant that he did not see himself as much of a researcher anyway. Michael himself said that he felt that Tom and Jerry contributed to the problem every time they accepted discussing and resolving problems that were in his portfolio with the others. Tom and Jerry became very angry about these responses. Michael was chastised for not being enough of an initiative taker while the other researchers were reminded that Case B was not the traditional academy and that the ambition was to stamp out all vestiges of seniority based hierarchy. People were going to be assigned to tasks on the basis of their fitness for that task. The tensions among the members of the research team continued to multiply until two of them left the organisation.

Tom and Jerry clearly thought that Michael's colleagues did not accept him because they felt that he was their junior in terms of academic ranking. While this interpretation may not have been completely off the mark, the actual explanations given by those concerned including Michael took up other issues which were clearly relevant, but which Tom and Jerry ignored. I discussed this particular issue with another member of the organisation who was part of the founding group and knew Tom and Jerry well. He referred to this as a persistent problem in the organisation, which he 
described as management by vision. In his view Tom and Jerry used the organisation's vision as a conflict resolution tool and a mechanism for retaining control rather than as a device for creating shared meaning. Thus, disputes were settled by reference to the vision alone and not to the substance of the claim. Further discussions revealed that despite their attempts to delegate, Tom and Jerry jealously guarded most of the information about finances, contracts, etc. from other members of the organisation so that even if his colleagues had turned to Michael for help on these issues, he would have had to go to Tom and Jerry to resolve these problems.

One aspect of the above anecdote may be described as a textbook case in bad leadership that can occur even in corporate entities. This is the problem of a management team who are not interested in the details of day-to-day management, but still want to retain control of such minutiae. A second aspect, however, is related to the particular ambivalence of academics towards management and the fact that they do not hold management skills in especially high regard. This came out quite clearly when one of the respondents argued that he interpreted Michael's acceptance of this task as a self-evaluation of Michael's competence as a researcher.

The peculiar need for management and the unwillingness to accept management also captured in this incident and the respondents' telling of their interpretations. For example, everyone agreed that the issues Michael identified needed to be addressed and that it was more efficient to address them in a forum such as the meeting. Yet when the meetings were actually convened they did not work. One reason was that Michael did not sit on the information necessary to deal with these problems and in this respect his colleagues were quite right in assuming that he did not.

Michael's colleagues were prepared to accept him as office manager, but not as research manager. This unwillingness seemed to have been premised on two criteria. One was they did not think that Michael was an experienced enough researcher to be effective or credible in the role of research leader. A second was that given the information that was available to his colleagues about Michael's new role, the research manager role seemed to be an entrepreneurial initiative taken by Michael himself.

One may also empathise with Tom and Jerry's desire to break with academic norms and their request that Michael's appointment be treated as such. This point of view, however, ignores several aspects of the situation. An important one of these is that academic research is distinguished from other kinds of work by an intimate connection between the social processes of work organisation, of which leadership is one, and the cognitive content of that work. This is incidentally a point that corporations have been confronting since the advent of knowledge intensive work in industry and the increasing realisation that traditional management techniques are unable to provide a nurturing environment for knowledge workers (Despres \& Hiltrop, 1995; Grant, 1997).

Had Case B been a department at the same universities at which it is located, this incident would have played out in a whole different way. In the first place resource needs for projects would be floated at the departmental meeting or 
quietly discussed with the head of department who may not necessarily have been a senior researcher, but whose appointment would have been approved by all departmental members. In fact, in this instance the departmental structure when functioning would have been much more agile at leveraging this issue than the structure which Tom and Jerry were trying to build.

The move from the departmental structure governed by the complex apparatus that has evolved in the university organisation to a semi-autonomous research centre often leaves the researchers who found Mode 2 institutions without much of this infrastructure which they have taken for granted. An inevitable result of this is that such persons soon discover, like Tom and Jerry, that: relating to junior colleagues and others becomes a management and leadership task since they are now not qjust colleagues but also employers; decision making becomes more sensitive and requires more negotiation in order to balance the needs of the organisation that one is building with that of its more resourceful and older strategic partner, the university and visions are necessary to make sense of what will initially be a loosely connected set of individual projects and project workers but cannot function as a stand alone normative system.

Shove (2000) highlighted one of the more challenging dilemmas associated with leadership in Mode 2, i.e. finding a way of moving the centre from being dependent on the skills and contacts of a few well known researchers to creating a team. This manoeuvre involves balancing the need to take responsibility for mentoring and helping junior colleagues to develop against the possibility that the inevitable mistakes that they will make while learning would damage the centre's reputation or spoil its chances of landing a major project. Institutionalisation of Mode 2 research also implies that researchers have to stop seeing each research project as a discrete event and begin to treat projects as a part of a process of institution building. All of these take time and require an environment in which trust building can be successfully achieved.

\section{Interface with the University}

Mode 2 centres are often strategically linked in a number of ways to discipline based departments ranging from sharing staff to shared responsibility for teaching and supervision. Such linkages can vary in form from informal deals between individuals to formal contracts with carefully delineated responsibilities. Whatever the nature of the arrangement, it has to be managed in order to derive the best benefit for both partners. Mode 2 centres are dependent on relations with university departmentsò in order to retain access to a number of phenomena that are critical to individual academic careers, as well as for the continued viability of the centre qua organisation. This need for interface with departments places pressure on Mode 2 centres because: (a) the institute has to have a number of researchers who are both well respected in the academic community and are able to navigate the murky waters of university administration; (b) these individuals must share their contacts and network into the university with other employees at the centre and (c) the institute has to develop 
protocols for managing the shared tasks with the department. These tasks can be easily mismanaged because researchers are often strong individualists and guard their network contacts jealously. Thus, it cannot be assumed that merely having an espoused policy at the centre of sharing contacts will yield positive results.

Likewise, academic reputations are in part constructed on word of mouth and nowhere is this more so than in Mode 2 where networks and personal contacts are tradeable currencies (Shove, 2000). Thus, if one researcher gets a reputation for being 'difficult' others will not only avoid working with him, but anyone they believe is closely allied or dependent on that person. An example taken from Case A can be used to illustrate this point. The institute had been awarded a large contract, which included three discrete, but interrelated large projects. Each project was the individual responsibility of a three-person research group that had joined the institute. The existing staff at the centre was too busy to take on more work so it was understood that one of these projects would have to hire in new staff and that the respective project leader, Jim would take care of this. Two years into the project and four research assistants later, the project was behind schedule and Jim was having difficulty recruiting new personnel. After sometime it became clear that Jim had such a poor reputation as a project leader that no one at his level would work with him and they actively discouraged their former $\mathrm{PhD}$ students from taking jobs in his projects. The management of Case A soon began to realise that they had two problems on their hands. One was to ensure that the project met its deliverables to save the centre's reputation and the other was to politely ask Jim to leave while making it clear to his other colleagues that they were welcome to stay on if they wished.

Organising in Mode 2 must be particularly sensitive to a number of other aspects of academic culture. This point cannot be overemphasised in an era where importing ideas from the corporate world to the university is de rigueur. Some of the more important items on this checklist include: a.) Sharing contacts will be construed by somefl researchers as helping the competition since access to teaching assignments, supervision, recruiting staff, etc. is highly valued currency if one is trying to construct an academic career from Mode 2, thus what might be good for the centre as an organisation may not be in the best interests of individual employees at the centre; b.) The fact that the employees at the centre are part of the same team does not imply that they are all regarded as equally competent by their university employed colleagues. Academic communities are notorious for having divergent informal evaluations and opinions of each others competence and c.) The ability of Mode 2 centres to become credible alternative academic careers to Mode 1 is dependent on a number of factors that lie outside of the boundaries of the centre. The status quo in Europe shows that these developments are intensely local i.e. they vary across nations and even within universities (cf. Potì \& Reale, 2000; Benner \& Sandström, 2000). On one hand, this diversity makes it difficult to develop any model for leadership of Mode 2 centres. On the other, it creates tremendous opportunities for persons who lead such centres since if 
they are sufficiently proactive they can actually shape both the context for leadership, as well as the expectations of leadership in such centres. This can be achieved through actively seeking information from other centres both local and international and using this information to suggest to university administrators how the interface with the centre can develop as well as provide models to employees as to how their careers can develop in such a setting.

\section{Interface with Funding Agencies}

Nowhere is the need for management in Mode 2 research more evident than in the relations between research centres and project or programme funders. Relationship management, always a challenge for academics, increases in complexity in Mode 2 for reasons such as the iEncrease in the popularity of research funding steering instruments that tie funding or make it conditional on stakeholder/user involvement in the project. Gibbons et al (1994) and Nowotny et al. (1999) refer to this process as the contextualisation of knowledge production and this more than any other feature may be said to set Mode 2 apart from Mode 1 . The implications of contextualisation for how knowledge is validated and how Mode 2 research is institutionalised are most significant. I shall focus on the latter, but there are a number of ways in which the two issues are linked to each other and ultimately to other more thorny issues such as academic freedom and a redefinition of the social responsibility of science. Nowotny et al. (2001:110) depict contextualisation in the following way:

A shift from a 'segregation' to an 'integration' model has led to an opening up of formerly tightly-knit scientific communities, held together with strong collectivist beliefs, practices and social organisation. As a result ' users' enter the picture; potential markets matter and funding sources become crucial.

That user involvement has the potential for creating knowledge that is more informed by its context is undeniable, but this does not automatically translate into politically correct knowledge production in the way that Nowotny et al. (2001) assumes.

Tenured researchers working on projects tended to develop their research questions with more of an eye to the internal market (discipline) than to the needs of users, real or imagined. Tied funding was developed to discourage this practice and induce more negotiation between science and society about the objects of inquiry. While this goal is laudable and perhaps not a new one on the science policy agenda, designing mechanisms to achieve it is not as straightforward as implied by the inputoutput models that seem to be the rule in science policy. Between the intended input of stakeholder involv $\mu$ ement in knowledge creation and the output of knowledge is a range of possibilities for unintended consequences. For instance, a situation of radical dependence i.e. $100 \%$ soft funding, can bring about a competitive situation similar to that which private firms experience. Funding sources and potential markets have to be sought out, courted and research has to be tailored to attract their attention. This will in some instances-just as it does in business- involve creating markets. In fact, the strong realist assumption about the relation between the knowledge available and market demand or users' 
needs that informs most research policy accounts is increasingly being challenged as Mode 2 becomes more pervasive.

The sustainability of Mode 2 centres and programmes is dependent on keeping a fairly stable research group together which is in turn a function of the group's capacity to land a certain number of projects per year that are financially rewarding. Churning out a project proposal that can capture the funding agencies and/or stakeholders' imagination, as well as provide enough leverage for researchers to be able to develop academically interesting results is one of the most important prerequisites for successfully managing the interface with funders. Raising enough money to employ oneself and others is a first step, but keeping the more productive younger researchers at the centre is tied to having research projects that will provide the material for intellectually challenging tasks and publication possibilities. Thus, the continued survival of Mode 2 centres is dependent on this marriage of good salesmanship with an eye for a commitment to research for its own sake. Mode 2 researchers will of necessity be co-producing needs with users in some instances and in others creating markets for knowledge that they have identified as relevant. Several accounts from Mode 2 point to this constructedness of utility and users that is a central part of the Mode 2 phenomenon (cf. Shove \& Rip, 2000; Rappert, 1999).

There are a number of management implications that flow from accepting this constructed user and utility thesis both at the level of managing science as a whole and at that of managing the institutionalisation of Mode 2. I will con- fine myself to the latter here. Admittedly much of the constructing utility and user profiles is dictated by the fact that Mode 2 knowledge production is still parasitic on Mode 1 for its value system, career trajectory and criteria for evaluating knowledge. Reasoning from this one may argue that this construction work will therefore decrease in importance as Mode 2 knowledge production matures and develops its own norms and epistemology. Those charged with managing Mode 2 should therefore try to straddle the two worlds as best they could while waiting for the new dawn. This is in my view a rather naïve vision. In the first place, knowledge production in science has always involved some element of construction. In the good or bad old days, this varied from constructing research questions and even results in ways that would ensure that they did not offend the Church. Once the Church's influence reduced, construction work continued; only this time it was to create or maintain disciplinary boundaries. Finally, one of the points on which researchers and users do converge is that collaboration does bring new insights to both parties. This, however, is to a large extent dependent on the fact that both communities have autonomous but connected paths of development.

\section{Conclusion}

One might argue that many of the problems highlighted above can be addressed by applying some of the insights that organisation studies have developed over the years through observation of problems in the public and private sectors. Leadership, for example, is a very popular and well-researched issue 
within organisation studies. Although there are many aspects to this discourse that one would not like to see transferred to the university context, issues such as those described in the example in Case $B$ are exhaustively treated in the literature. Understanding that leadership is a characteristic that must be motivated and finding the criteria for motivation that would be adequate to the group that is to be led and the substance of the work task is a basic rule of thumb in management that can be easily applied in the context of Mode 2 institutes.

The issue of interface both with funding agencies and the university is a more complex problem. The reason is that this problem intersects with a number of others that are strictly speaking not management issues for Mode 2 institutes themselves but are part of the larger context of the Mode 2 debate itself. For instance, one might well argue that the interface with the university is a problem that has to be handled by the university as well as Mode 2 institute managers. Managers may improve their understanding of the university's routines and even develop new routines together with the university. One can ask, however, how relevant is it for universities to make such changes given that Mode 2 institutions are often temporary? There is no easy answer to this question particularly since the boundaries between Modes 1 and 2, although never as distinct as represented in the Mode 2 thesis, are becoming even more blurred than previously. Regardless of this there are good reasons for universities to bother themselves about changing routines and for creating a general understanding of so called Mode 2 phenomena. One is that Mode 2 institutes repre- sent one way in which the university through its research activities reaches out to the rest of society. Thus, facilitating that interface and ensuring that it works smoothly for all parties, is important to the university. A second is that some Mode 2 institutes are no more than temporary networks which have been developed to exploit a particular opportunity. There is a need for administrative oversight to be developed to ensure that these activities do not merely exploit the university's resources (e.g. personnel and brand name) but also add value. Case B one may argue is a typical example of such a network.

Finally, if we view Mode 2 not as a separate phenomenon but as part of the overall ongoing process of transformation of European universities, the management issues highlighted above provide insights into some of the organisational changes that would have to be made as part of a more general effort to reposition the university's role in society.

\section{References}

Behrens, T.R. \& Gray, D.O.

2001 "Unintended consequences of cooperative research: impact of industry sponsorship on climate for academic freedom and other graduate student outcome." Research Policy, 30, 2: 179199

Benner, M. \& Sandstrom, U.

2000 "Inertia and change in Scandinavian public-sector research systems: the case of biotechnology." Science and Public Policy, 27: 443-454.

Bourdieu, P.

1988 Homo Academicus, Stanford University Press.

Delanty, G.

2001 Challenging Knowledge:The University in the Knowledge Society. Buckingham, UK: Open University Press. 
Demeritt, D.

2000 "The new social contract for science: accountability, relevance, and value in US and UK science and research policy." Antipode, 32, 3: 308-329.

Despres, C. \& Hiltrop, J.M.

1995 "Human resource management in the knowledge age: current practice and perspectives on the future", Employee Relations, 17, 1: 9-23.

Evans, G.

1999 Calling Academia into Account, Buckingham, UK: Open University Press.

Fujigaki, Y. \& Leydesdorff, L.

2000 Quality Control and Validation boundaries in a Triple Helix of university- industry-government: Mode 2 and the future of university research, Social Science Information 39,4: 633-655.

Fuller, S.

1997 Science. Buckingham, UK: Open University Press.Gibbons, M., Limoges, C., Nowotny, H., Schwartzman, S., Scott, P. and Trow, $\mathrm{M}$.

1994 The new production of knowledge: The dynamics of science and research in contemporary societies. London: Sage.

Gibbons, M., Limognes, C., Nowotny, H.,

Schwartzman, S., Scott, P. \& Trow, M.

1994 The New Production of Knowledge. The Dynamics of Science and Research in Contemporary Societies. London: SAGE Publications.

Godin, B.

1998 "Writing performative history: the new Atlantis?" Social Studies of Science 28: 465-483 Review of Gibbons, M., et al., 1994, The New Production of Knowledge.

Grant, R.

1997 "The knowledge-based view of the firm: Implications for management practice" Long Range Planning, 30, 3:450-454.

Guston, D. \& Kenniston, K.

1994 "Introduction: The Social Contract for Science" In Guston, D. and Kenniston, K. (eds.) The Fragile Contract, 1-41 Cambridge and London: MIT Press.
Kuhlmann, S.

2001 "Future governance of innovation policy in Europe-three scenarios.” Research Policy, 30: 953-976.

Martin, B.

2001 The Changing Social Contract for Science and the Evolution of the University" SPRU Working Paper available at: http://www.researchineurope.org/ nprnet/documents/index.htm\#papers

Martin, R.

1999 The regional dimension in European public policy: convergence or divergence? Basingstoke: Macmillan.

Nowotny, H., Scott, P. \& Gibbons, M.

2001 Re-Thinking Science: knowledge and the public in an age of uncertainty. Cambridge, UK: Polity Press

OECD

1998 University Research in Transition (Paris, OECD).

Peterson, J. \& Sharp, M.

1998 Technology Policy in the European Union. St. Martins Press: New York.

Pinch, T.

1990 "The sociology of the scientific community," in Olby, R. Cantor, G. Christie, J. and Hodge, M. (eds.) Companion to the History of Modern Science, London: Routledge.

Platt, J.

1996 "Has Funding made a difference to research methods?" Sociological Research Online www.socresonline.org. uk/socresonline/1/1/5.html (10/01).

Potí, B. \& Reale, E.

2000 "Convergence and Differentiation in Institutional Change among European Public research systems: the decreasing role of public research institutes, Science and Public Policy, 27: 421-431.

Pritchard, R.M.

1998 Academic Freedom and Autonomy in the United Kingdom and Germany, Minerva 36,2: 101-124.

Potì, B. \& Reale, E.

2000 Convergence and differentiation in institutional change among European public research systems: the decreasing role of public research institutes, Science and Public Policy, 27,6: 421431. 
Rappert, B.

1995 "Shifting Notions of Public Accountability in Public- and Private-Sector Research in the UK: Some central concerns," Science and Public Policy, 22: 383-390.

Rappert, B., Webster, A. \& Charles D.

1999 "Making sense of diversity and reluctance: academic industrial relations and intellectual property," Research Policy 28,8: 873-890.

Rappert, B.

1999 "The Uses of Relevance: Thoughts on a Reflexive Sociology," Sociology 33,4: $705-723$

Shapin, S.

1994 A Social History of Truth: Civility and Science in Seventeenth-Century England. Chicago: University of Chicago Press

Shove, E.

2000 "Reciprocities and Reputations: new currencies in research," Pp. 63-80 in Jacob, M. and Hellström, T. (eds.) The Future of Knowledge Production in the Academy, Buckingham, UK: Open University Press.
Shove, E. \& Rip, A.

2000 "Users and Unicorns: a discussion of mythical beasts in interactive science," Science and Public Policy, 27,3: 175182.

Slaughter, S. \& Leslie, L.

1997 Academic Capitalism: Politics, Policies, and the Entrepreneurial University. Baltimore: The Johns Hopkins University Press.

Weingart, $\mathrm{P}$.

1997 “From `finalization' to ‘mode 2': old wine in new bottles?" Social Science Information 36: 591- 613

Ziman, J.

2000 Real Science: What it is, and what it means, Cambridge, UK: Cambridge University Press

Merle Jacob

Department of Innovation Engineering and Management

Chalmers University of Technology,

Sweden

merjac@mot.chalmers.se 